\title{
LATENT CARCINOMA OF THE PROSTATE
}

\author{
BY \\ $2 x$ \\ G. S. ANDREWS \\ From the Department of Pathology, University of Bristol
}

(RECEIVED FOR PUBLICATION, APRIL 22, 1949)

The incidence of carcinoma of the prostate in 1947 in the United Kingdom, according to the Registrar-General, was $0.98 \%$ of all male deaths. Nevertheless several writers (Muir, 1934 ; Moore, 1935 ; Rich, 1935 ; Gaynor, 1938 ; Kahler, 1939 ; Baron and Angrist, 1941; Luppi, 1947) have reported a much higher incidence of carcinoma in prostates removed at routine necropsy when the condition was unsuspected. The reported figures range from $2.1 \%$ to $46 \%$. This variation can only be attributed to differences of method of examination or of criteria of malignancy. Since it is important to establish the true incidence of latent carcinoma of the prostate it was decided to make a thorough study of prostates removed at necropsy, and to employ a careful and uniform technique.

\section{Material and Methods}

One hundred and forty-two prostates were studied. These had been removed at necropsy from males between the ages of 15 and 79 years in whom the diagnosis of carcinoma of the prostate had not been made clinically or on gross examination at necropsy.

Each prostate was dissected free from surrounding tissue and its volume measured by reading the volume of fixing fluid displaced by the gland on immersion in a measuring cylinder. It was then fixed whole for ten days in $10 \%$ formol saline (one part commercial formaldehyde with nine parts normal saline), buffered

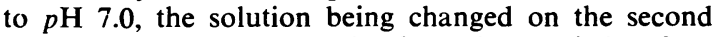
day. Fixation with corrosive formol was tried at first, but formol saline gave better nuclear detail and was satisfactory even with the largest gland with a volume of $105 \mathrm{ml}$. Prostates were obtained up to 54 hours after death.

The glands were first cut coronally through the urethra, thus dividing them into anterior and posterior portions. Each portion was then placed on the machine used for slicing the brain. This consists of the base and three sides of a shallow wooden box with sheets of glass within it. The number of glass sheets was adjusted to allow a space of $4 \mathrm{~mm}$. between the top of the box and the surface of the glass, so that a long knife laid on the top of the box could be used to cut slices $4 \mathrm{~mm}$. thick. In this manner the prostate was completely divided into blocks about $4 \mathrm{~mm}$. thick, each of which was numbered. Since the prostates varied considerably in size and shape it was sometimes more convenient to section them sagittally, but in every case the whole gland was divided into blocks. Some variation in the thickness of the blocks was inevitable, but none was thicker than $5 \mathrm{~mm}$. Blocks thinner than $4 \mathrm{~mm}$. were difficult to work with, particularly if they were large, as they became distorted.

Dehydration and clearing were carried out slowly with an alcohol-butyl-benzene series. The blocks were embedded in paraffin and sections cut at a thickness of $8 \mu$ from the same surface of each block. When small calculi were encountered during cutting use was made of Ebner's solution as advised by Lendrum (1947). As a routine measure the sections were stained with Weigert's haematoxylin and 1\% alcoholic eosin.

By this method a series of sections was obtained from each prostate, the sections being at roughly $4 \mathrm{~mm}$. intervals right through the gland. Moore (1935) calls this a method of "step-section."

\section{Criteria of Malignancy}

Since adenocarcinoma of the prostate is often composed of small, well-differentiated acini in which nuclear changes and mitotic figures are rare or absent, it is necessary to scrutinize carefully the relationship of epithelium to stroma. Prostatic acini whether normal or hypertrophic are surrounded by a stroma propria, composed of fibromuscular and a little elastic tissue, which closely invests them and faithfully follows the contour of the acinus even into the projecting papillae. Together the acinus and the stroma propria form a single unit around which the supporting stroma of the gland sweeps (Fig. 1). Most normal and hypertrophic acini also possess a basal layer of epithelial cells which are flattened or fusiform in shape and are arranged horizontally around the acinus. There are, however, certain acini which do not possess a basal layer of cells, but these still retain the normal relationship to the stroma propria (Fig. 2). Malignant acini have neither a basal layer of epithelial cells nor a stroma propria. The absence of a basal layer, therefore, does not necessarily indicate malignancy, but the relation- 


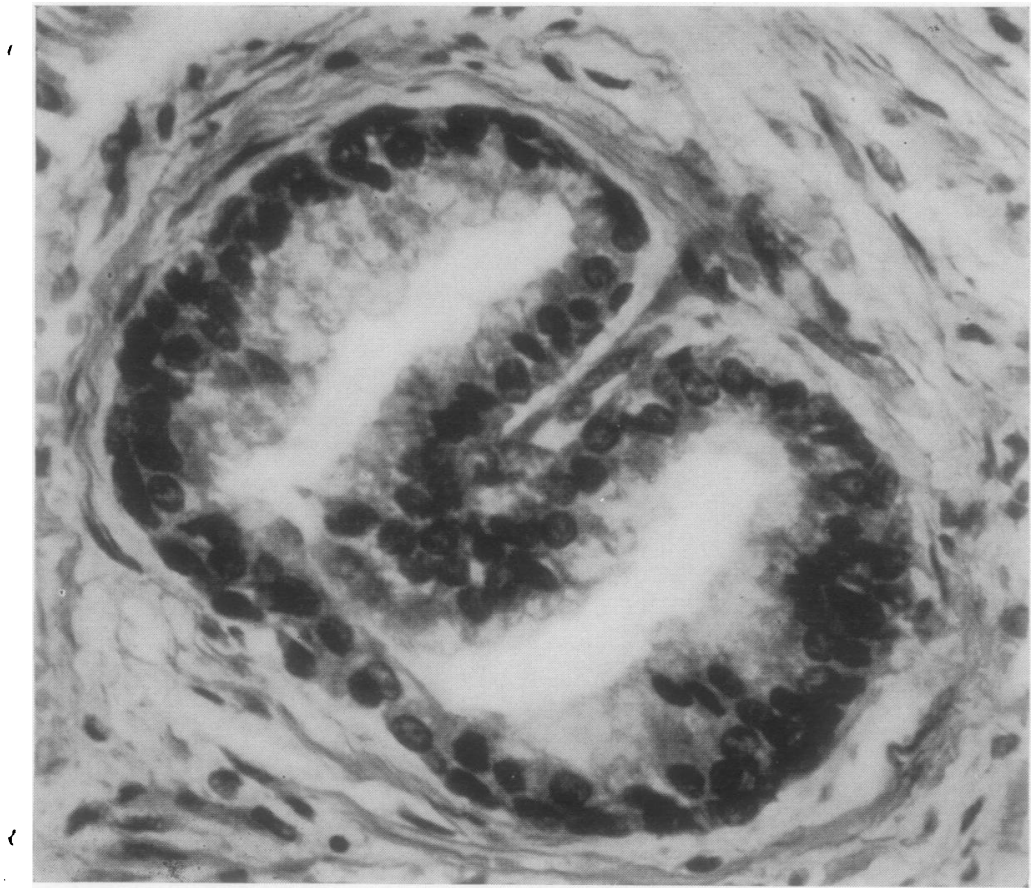

Fig. 1.-Normal prostatic acinus with basal layer of epithelial cells and stroma propria which can be followed into the papilla. $\times 550$. invasion, and invasion of the blood vessels. Perineural $\overrightarrow{\vec{F}}$ lymphatic invasion was lookedfor particularly in every case. $\frac{}{0}$

\section{Results}

Carcinoma was found in $17(12 \%)$ of the 142 prostates? examined. It was not found? before the age of 40 . The $\vec{\omega}$ incidence after 40 is shown in Table I. Statistical analysis shows that there is a signifi- $i$ cant rise in the incidence of $\omega$ carcinoma between the sixth $\vec{\varphi}$ and seventh decades $(P<0.01)^{\vee}$ but not beyond the seventh. This does not agree with the $\vec{\nabla}$ observation of Moore (1935) who concluded that the inci- $\frac{c}{\omega}$ dence of carcinoma increased $\stackrel{+}{-}$ steadily up to a maximum

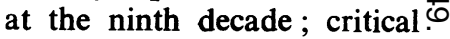
examination of his figures? shows that the increase was not really statistically significant.

ship of the acinus to its stroma is of great importance and is particularly striking when malignant acini are invading muscle.

Moore (1935) drew attention to the tendency of carcinoma of the prostate to spread by the perineural lymphatics, and Kahler (1939) describes this as the most valuable criterion in its diagnosis. This form of infiltration is seen frequently and extensively even in small tumours.

In view of the special characteristics of carcinoma of the prostate the diagnosis of malignancy was based on the observation of abnormal stromal relationship together with any three of the following: nuclear changes, mitotic figures, anaplasia, heteroplasia, lymphatic

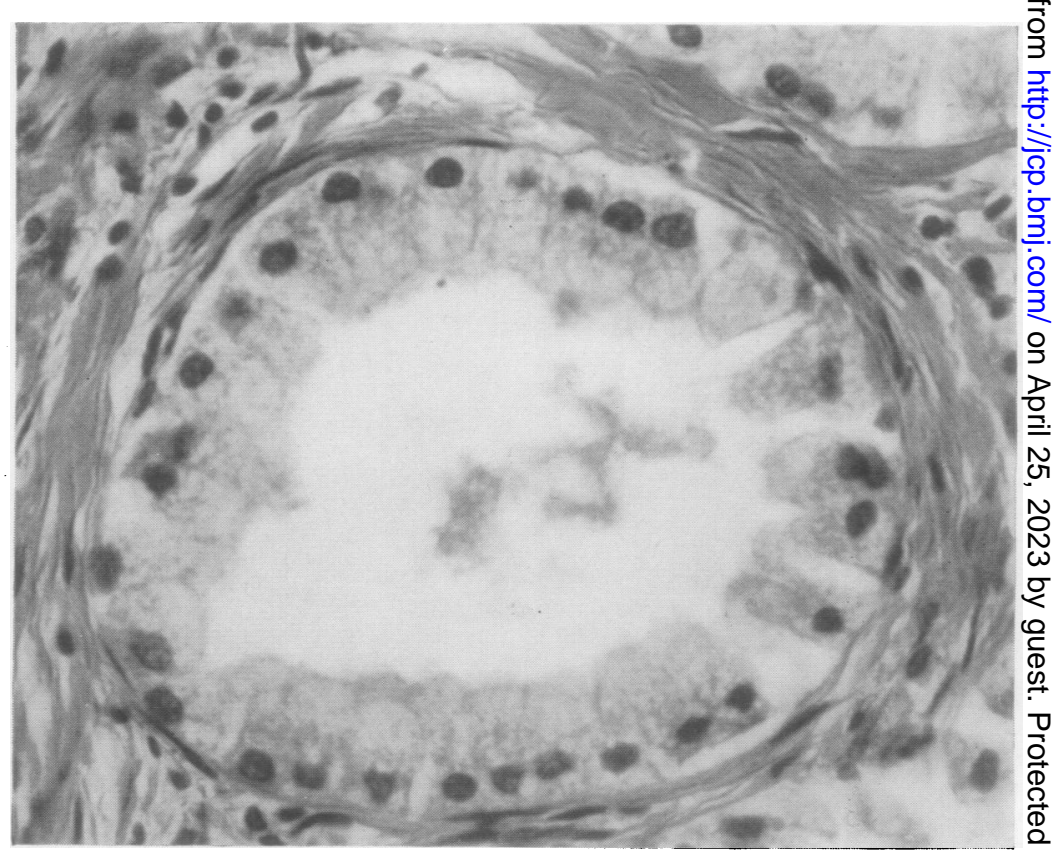

FIG. 2.-Normal acinus without basal layer of epithelial cells but with normal stroma propria. $\times 550$. 
TABLE I

INCIDENCE OF CARCINOMA AND BENIGN HYPERTROPHY

\begin{tabular}{|c|c|c|c|c|}
\hline $\begin{array}{c}\text { Age } \\
\text { Groups }\end{array}$ & $\begin{array}{c}\text { Total } \\
\text { Number } \\
\text { of } \\
\text { Prostates }\end{array}$ & $\begin{array}{c}\text { Prostates } \\
\text { without } \\
\text { Carci- } \\
\text { noma }\end{array}$ & $\begin{array}{l}\text { Prostates } \\
\text { with } \\
\text { Carci- } \\
\text { noma }\end{array}$ & $\begin{array}{c}\text { Prostates } \\
\text { with } \\
\text { Benign } \\
\text { Hypertrophy }\end{array}$ \\
\hline $\begin{array}{lll}40-49 & \ldots \\
50-59 & \ldots \\
60-69 & \ldots \\
70-79 & \ldots\end{array}$ & $\begin{array}{l}22 \\
38 \\
39 \\
22\end{array}$ & $\begin{array}{l}21 \\
36 \\
32 \\
15\end{array}$ & $\begin{array}{l}1 \\
2 \\
7 \\
7\end{array}$ & $\begin{array}{r}2 \\
23 \\
37 \\
22\end{array}$ \\
\hline
\end{tabular}

Site of Origin.-Lowsley (1930) has shown that the prostate begins to develop during the third month of foetal life as five groups of solid outgrowths from distinctive parts of the urethra. One group arises from the posterior wall of the urethra between the bladder neck and the ejaculatory ducts; one on each side from the lateral furrows of the urethra including the lower part; one from the posterior wall of the urethra below the ejaculatory ducts ; and one from the upper and anterior part of the urethra. A middle lobe, two lateral lobes, a posterior lobe, and an anterior lobe develop from these outgrowths. The middle lobe is bounded by the bladder superiorly, the urethra anteriorly, and the ejaculatory ducts posteriorly ; its ducts open into the posterior wall of the urethra above the ejaculatory ducts. The lateral lobes are situated on each side of the urethra and extend posteriorly and anteriorly, and their ducts pass posteriorly, then medially and anteriorly to end in the lateral furrows of the urethra. The posterior lobe is bounded anteriorly by the urethra, anterosuperiorly by the ejaculatory ducts, and posteriorly by the capsule ; its ducts end in the posterior wall of the urethra below the ejaculatory ducts. The anterior lobe is small and is situated in the median plane anterior to the upper part of the urethra ; its ducts end in the anterior wall of the urethra. The middle lobe may be absent occasionally. Lowsley states that the acini of the middle and lateral lobes may intermingle, but considers that a distinct layer of fibrous tissue separates the posterior and lateral lobes. Whether or not it is accurate to regard the prostate as sharply divided into lobes is debatable, but the divisions do serve as a rough means of siting lesions.

In one prostate the tumour was so extensive that it was impossible to determine its site of origin, and this was the only gland in which the middle lobe was involved and the seminal vesicles infiltrated. In four glands two separate areas of carcinoma were found. In two of these there was considerable difference in the size of the tumours, but in the other two the tumours were of similar size, thus supporting the view that prostatic carcinoma may be multifocal in origin (Moore, 1935). It was possible, therefore, to localize with fair accuracy the sites of origin of 20 small carcinomata. Twelve were confined to, or occurred maximally in, the posterior lobe and eight arose in the lateral lobes. This confirms the finding that carcinoma of the prostate occurs most commonly in the posterior lobe. The anterior lobe did not contain tumour in any case.

Method of Spread.-Eleven tumours in the posterior lobe and two in the lateral lobes arose just beneath the capsule, and in eight of these the capsule was infiltrated, thus supporting the observations of Rich (1935) and Gaynor (1938).

In all but four glands the tumours were confined to one lobe ; of these four, two, arising in the posterior lobe, had spread forwards on both sides of the urethra into the anterior part of the gland, but the other two, arising in the lateral lobes, had spread forward around the urethra into the lateral lobe on the other side.

Size of Tumours.-All the tumours except one could be roughly measured. The largest was $20 \times 20 \times 8 \mathrm{~mm}$. and the smallest $2 \times 2 \times 2 \mathrm{~mm}$. The tumours varied considerably within this range, the average volume being 718 c.mm.

Histology.-The tumours were all adenocarcinomata which varied in histological appearance but had certain features in common. In the main they were composed of small acini. Since Luppi (1947) has stated that senile acini and acini distorted by the pressure of "adenomata" in benign hypertrophy may be wrongly diagnosed as malignant, it is important to emphasize the differences between malignant and non-malignant small acini.

Small senile acini are shrunken and often distorted, They are usually lined by small irregular cubical or flattened cells with sinall pyknotic round or irregular nuclei (Fig. 3a). Cells with thin oval nuclei usually arranged perpendicularly to the lumen also occur and may predominate (Fig. $3 b$ ). The basal layer of cells usually has rounder and paler staining nuclei. In older glands the luminal cells are all flattened and the basal nuclei narrow and pyknotic similar to those of the lining layer (Fig. 3c). The cell outline is indefinite and the cytoplasm scanty, palely eosinophilic, and finely granular, sometimes being reduced to a thin rim around the nucleus. The stroma propria is always present and is thickened and collagenous. 

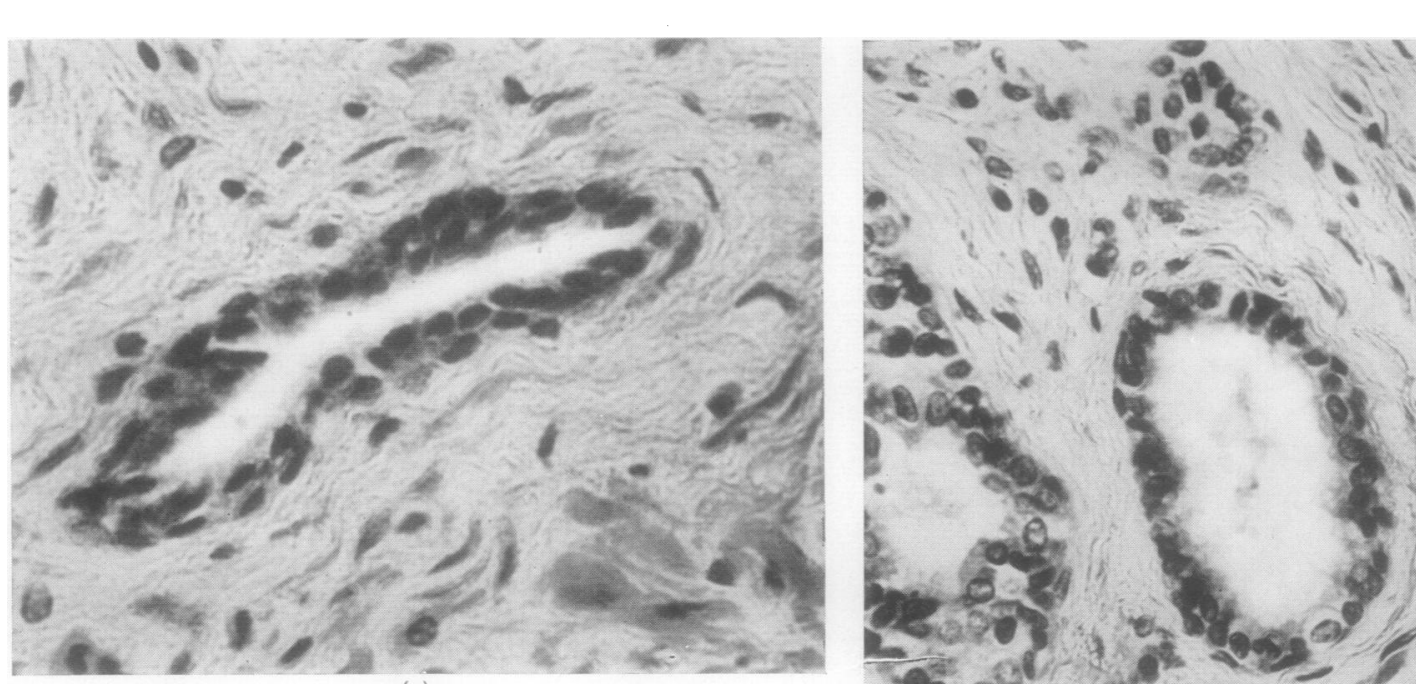

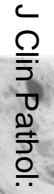

(a)

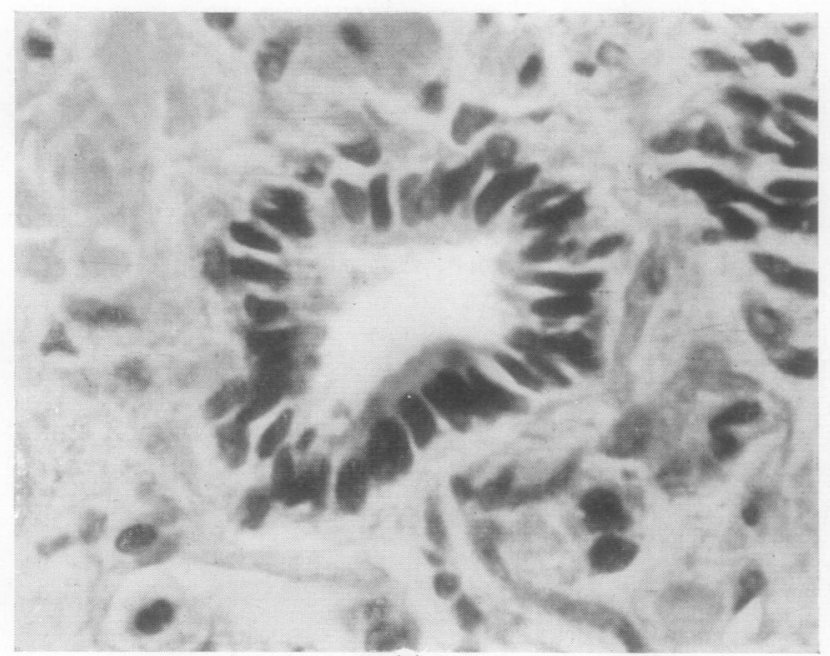

(b)

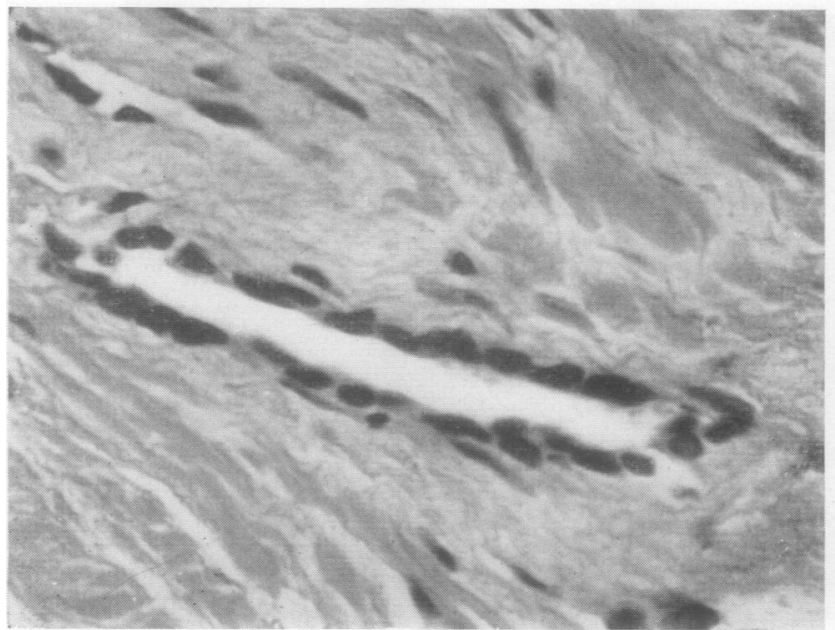

(c)
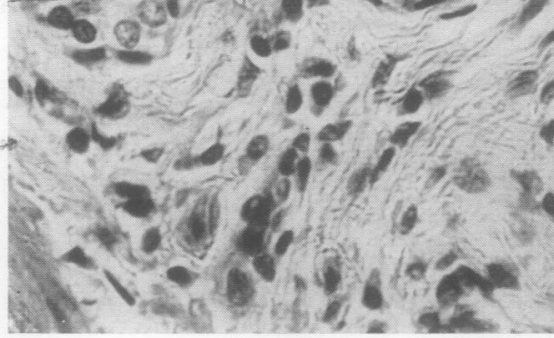

$\stackrel{\vec{F}}{\rightarrow}$

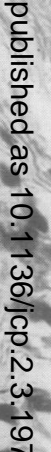

o.
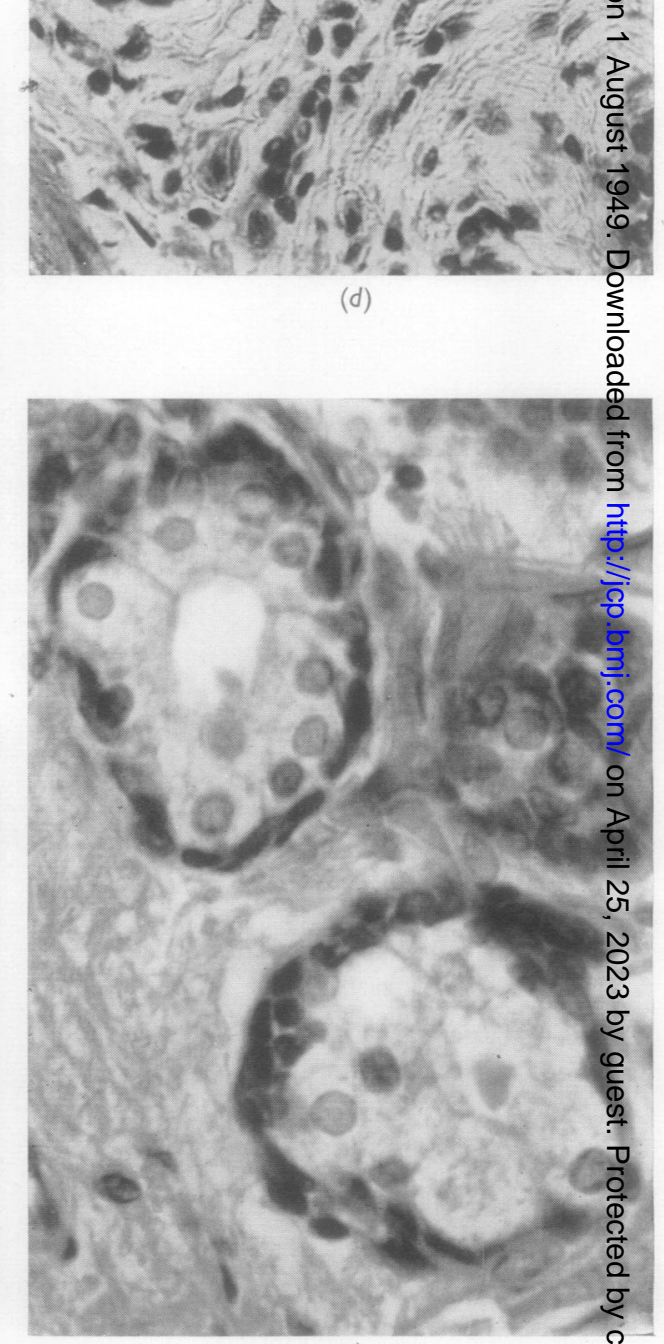

(e)

FIGs. $3 a, 3 b$, and 3c.-Small senile acini showing small pyknotic nuclei. $\times 803 . \quad 3 d$ and $3 e .-$ Small acini in benimn hypertrophy showing typical nuclei and cellular appearance with perinuclear vacuolation. $d \times 400, e \times 800 \frac{6}{7}$ 
Prostates with benign hypertrophy contain small senile acini, but other small acini are also present which are round or oval in shape, often in contact with one another and arranged in groups. These acini are lined by cubical cells with a finely granular, deeply eosinophilic cytoplasm or low columnar cells with clear reticular cytoplasm often with a faint eosinophilic rim at the luminal border. The cells are regular and the cell borders clear cut except when secretion is occurring. The nuclei are large, round or oval, and pale staining, with a delicate chromatin network. Perinuclear vacuolation of the cytoplasm often occurs (Fig. 3d). The basal cells possess thin oval, pyknotic nuclei which form a definite rim to the acinus (Fig. $3 e$ ). The stroma propria is wide and rather cellular, and sometimes there is a thin rim of hyaline material around the acinus between the basal layer and the stroma propria.

Small, distorted acini which are seen around the " adenomata" in benign hypertrophy are unusual only in shape ; their histological picture does not differ from that of the acini described above.

The small malignant acini which formed the main part of the tumours in this series were usually composed of cubical cells, but they varied in size and shape, some being rather flattened, but in one tumour giant forms were present. The malignant cells were definitely larger than those of the senile acini and were comparable in size to those of the small acini in benign hypertrophy but differed from these in their irregular shape and irregular luminal border. The cytoplasm varied; it was usually finely granular and eosinophilic but not so deeply staining as that of the small acini in benign hypertrophy. A small amount of eosinophilic secretion was occasionally present in the lumen of the acini. It is perhaps noteworthy that corpora amylacea were never seen in the carcinomatous areas. The nuclei of the malignant cells were larger than those seen in normal or hypertrophied prostates and were larger in relationship to the size of the cell. They were usually round but occasionally oval and varied in staining power. They had a definite chromatin network which was coarser than that of the nuclei in benign hypertrophy, and there was some condensation of the chromatin at the periphery of the nucleus. One or two prominent nucleoli were usually present. The basal layer of epithelial cells was never present, and the altered relationship to the stroma was most striking. The stroma propria was absent and the malignant acini had grown into the supporting stroma separating the muscle fibres and in many cases actually rupturing them (Fig. 4). These heteroplastic acini were present in every tumour, but, in addition, other small acini occurred which had the clear reticular cytoplasm of the normal adult epithelium, and gradation could be seen between these and the more usual eosinophilic cytoplasm, but even in these the large typical nucleus was usually present and the basal layer and stroma propria were always absent.

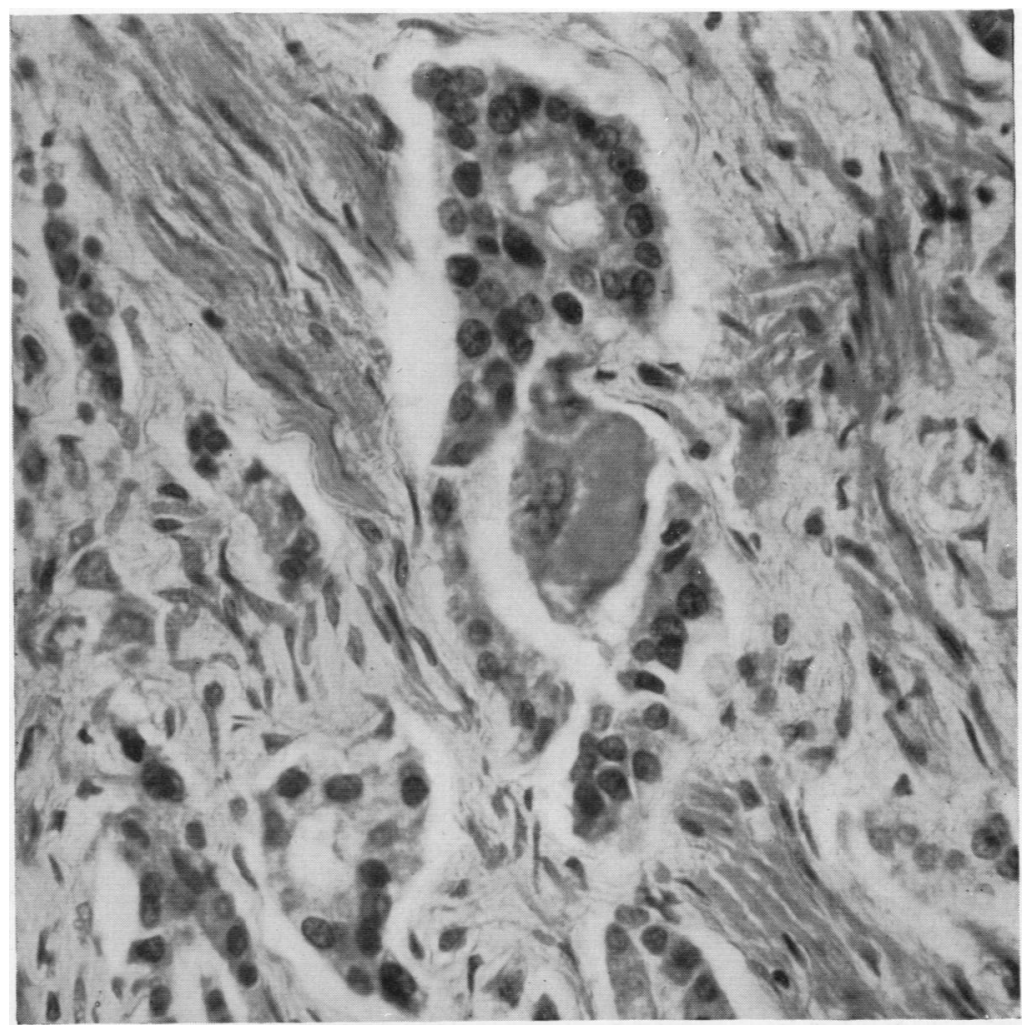

FIG. 4.-Typical small malignant acini rupturing a muscle bundle. $\times 400$. 


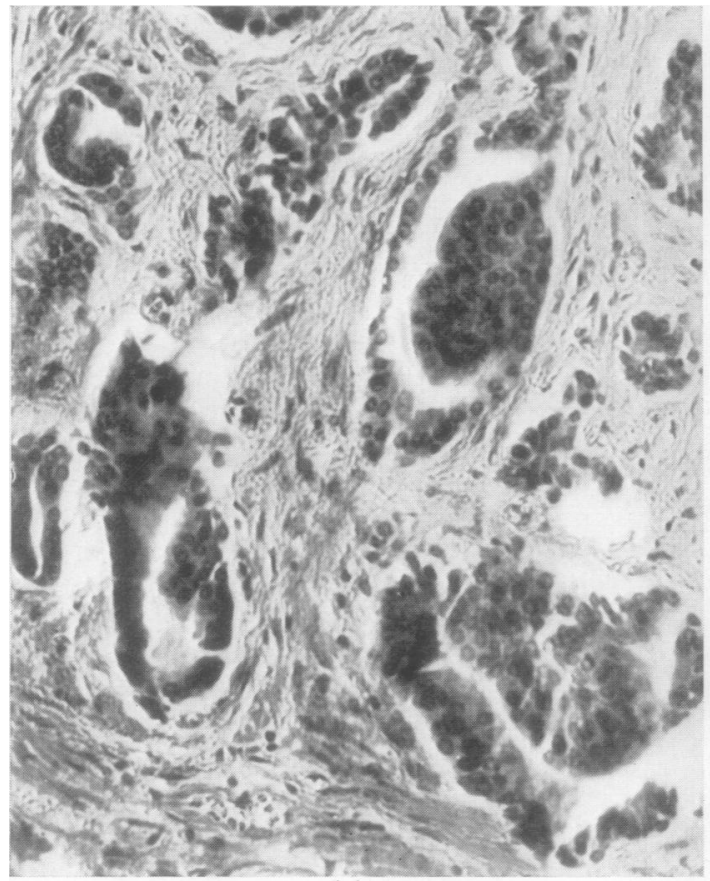

(a)

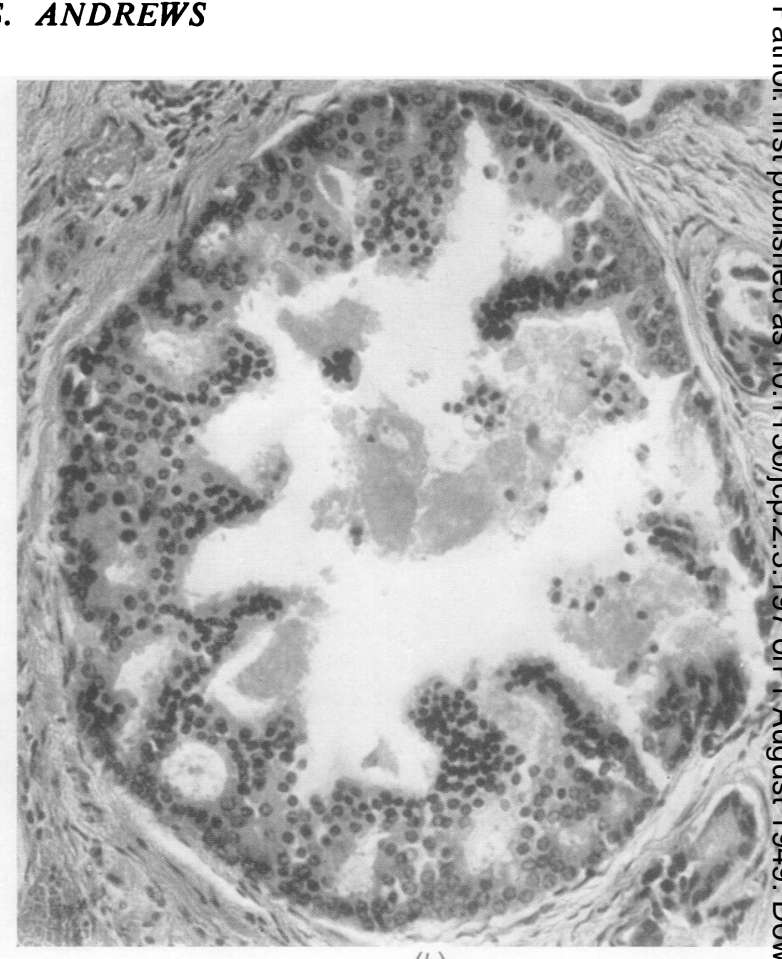

(b) 
The malignant acini were usually round or oval in shape, but many were distorted, the lumen having been reduced to a slit or absent, and the acinus consisted of two parallel rows of cells. This appearance depended, in some tumours, on the degree of de-differentiation and was commonly associated with areas of anaplasia. The cells lining these acini were large and irregular and appeared to be thrusting out processes into the surrounding stroma. Small aberrant acini also occurred composed of two crescentic cells joined at either pole with a lumen between them. In other tumours the distorted appearance was the result of stromal reaction produced by the tumour. A marked scirrhous reaction was present in four of the tumours

There were anaplastic areas in 14 of the tumours. These areas were in the main small, but in four they formed a considerable bulk of the tumours. In one tumour the cells had undergone mucoid degeneration and presented the typical signet ring appearance.

In addition to the small acini six tumours contained larger acini which showed intra-acinar proliferation of cells with a tendency to form small acini within the main acinus. The degree of proliferation varied. Some of the acini were small with one part of the wall composed of many layers of cells, or one or more cellular papillae projecting into the lumen (Fig. 5a). Others were much larger and were composed of large masses of cells with many small lumina within them so that they appeared as aggregations of small acini (see Fig. 5c) and resembled cribriform carcinoma of the breast (Muir, 1941). Every gradation could be seen between these two types, the common form being a large acinus with multiple cellular papillae, without a stromal core, often branched and united with their neighbours (Fig. $5 b$ ). None of these acini had a basal layer or a stroma propria, but the largest, apparently growing mainly by expansion, had compressed the surrounding stroma and produced a false capsule around the acinus. The cells forming these larger acini were similar to those forming the smaller acini in the same tumour, but they were usually slightly larger and more regular, the cytoplasm usually being eosinophilic and slightly granular, but again gradation could be seen between this and the clear reticular cytoplasm of adult prostatic epithelium. All the cells in the acinus had the same cytoplasmic appearance; there was no differentiation of luminal cells. The nuclei were similar to those of the small acini. Eosinophilic secretion was sometimes present within the lumen.

Abnormal nuclear forms occurred both in the small and the large malignant acini. These were mainly large and intensely pyknotic, but degenerate shrunken pyknotic nuclei with a crenated border were also present. These nuclear changes occurred in 16 of the 17 prostates with carcinoma. Mitotic figures were not seen in any tumour.

Perineural lymphatic invasion was present in 15 of the 17 prostates with carcinoma, and in five it was extensive. Most commonly there were one or two small heteroplastic acini crescentic in shape closely applied to the nerve (Fig. 6a). Sometimes longitudinal section of a nerve showed many small acini occupying the lymphatics along the whole

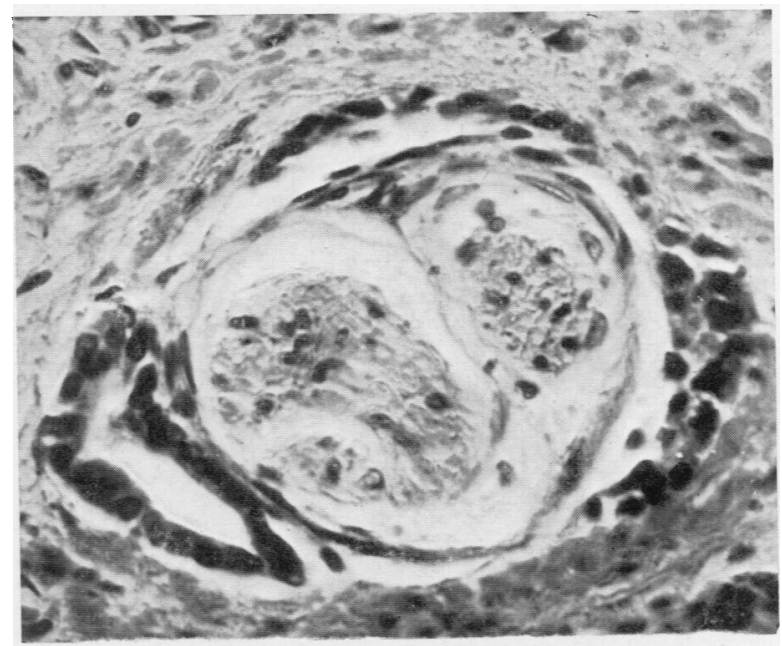

FIG. $6 a .-$ Common type of perineural lymphatic invasion. $\times 200$.

length of the nerve. It was often remarkable that the perineural lymphatics were invaded by the most differentiated acini in the tumour. Occasionally the lymphatics were filled with the intraacinar type of growth (Fig. 6b), showing that, although this type of growth appears to be mainly intra-acinar, the acini are definitely invasive. The extent of perineural lymphatic invasion appeared to depend more on the size of tumour than on the degree of anaplasia ; in the most anaplastic tumour it was only found after a prolonged search. It could be found, however, in the smallest tumours and must be considered an important and early method of spread of carcinoma of the prostate.

Invasion of blood vessels was not common. The malignant acini were often seen growing in the loose connective tissue around the blood vessels, but in only four glands was there definite evidence of invasion of the wall of small vessels, and in only one of these were tumour cells actually seen in the lumen. In one other gland the wall of a large vein had been invaded. 


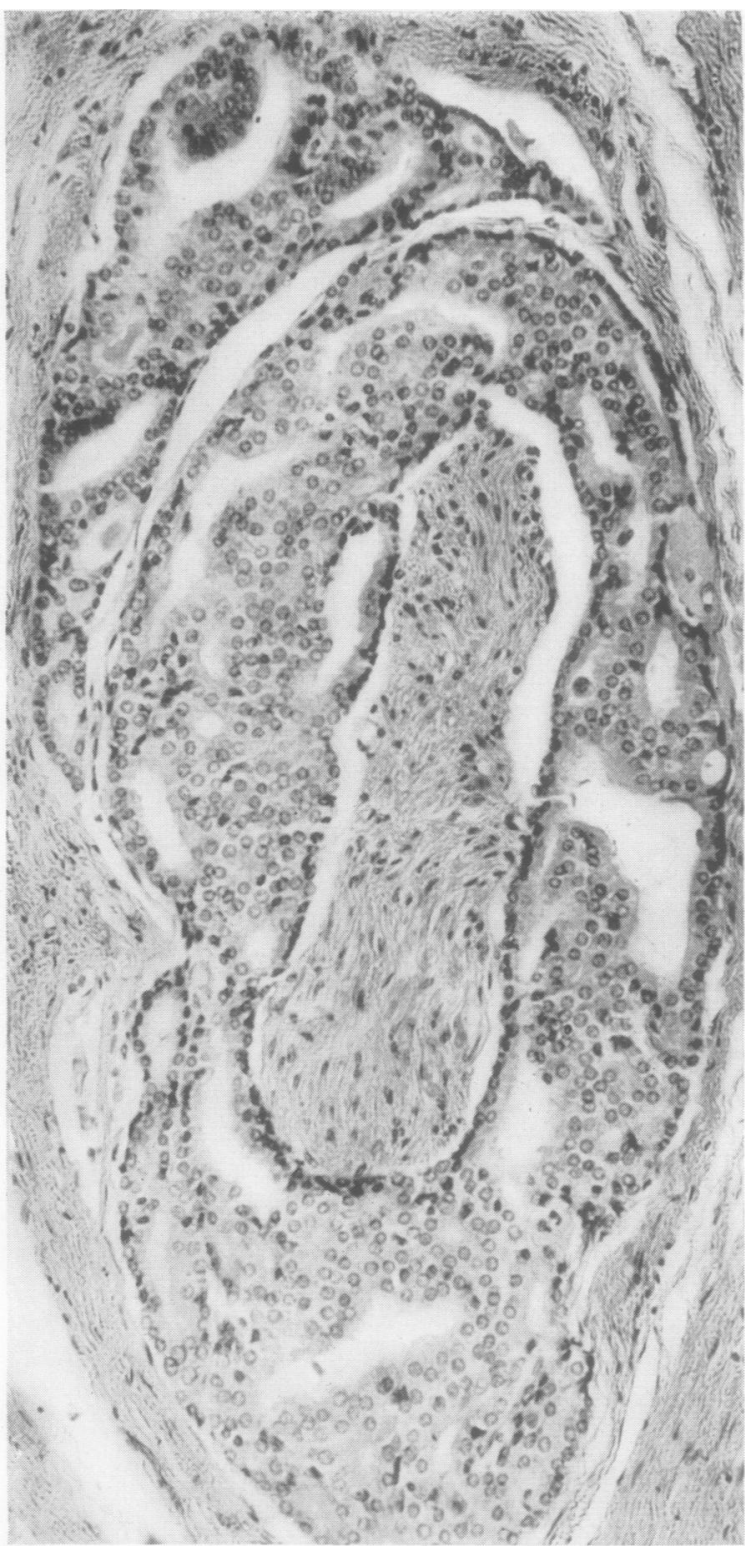

FIG. 6h.-Intra-acinar type of carcinoma in perineural lymphatics. $\times 200$.

Associated Pathological Conditions.- No pathological condition outside the prostate was found to have a significant connexion with carcinoma of that organ, but it is interesting that three of the patients with carcinoma of the prostate had carcinoma in other organs: these were carcinoma of the head of the pancreas with metastases, carcinoma of the colon with metastases, and a small carcinoma of the rectum. None of these tumours bore any resemblance histologically to the in dental carcinoma of the prostate and therefore could not be confused with it. The incidence ff carcinoma in other organs in the whole series $\overline{\overline{\underline{\varphi}}}$ f 142 was 47 . (In 500 consecutive routine necropsies on males over the age of 15 , performed before and during this investigation, the incidence of carcinoma, excluding carcinoma of the prostafe, was 134.)

Calculi were present in 31 of the 142 prostates studied, three of which also contained carcinon but in no case did the carcinoma actually arise in an area containing calculi. Similarly 22 of the 142 prostates showed duct obstruction, focal atrophy, and acute inflammation; three of thege also contained carcinoma, but in only one did the carcinoma actually arise near an area of inflammation. There is therefore no significant connexion between carcinoma and prostatic calcyli or inflammation.

Sixteen of the prostates with carcinoma atso showed the changes of benign hypertrophy. The seventeenth, from a man aged 49 , although large (volume, $30 \mathrm{ml}$.) did not show the histologielal changes of benign hypertrophy. Benign hype्ब్ trophy was not found in any gland before the age of 40 , and its incidence after that age is compared with carcinoma in Table I. Statistical analy (Table II) shows that benign hypertrophy and

TABLE II

InCIDENCE OF Normal AND CARCINOMATOUS Prosta急 WITH/WITHOUT BENIGN HYPERTROPHY OVER AGE OF 40

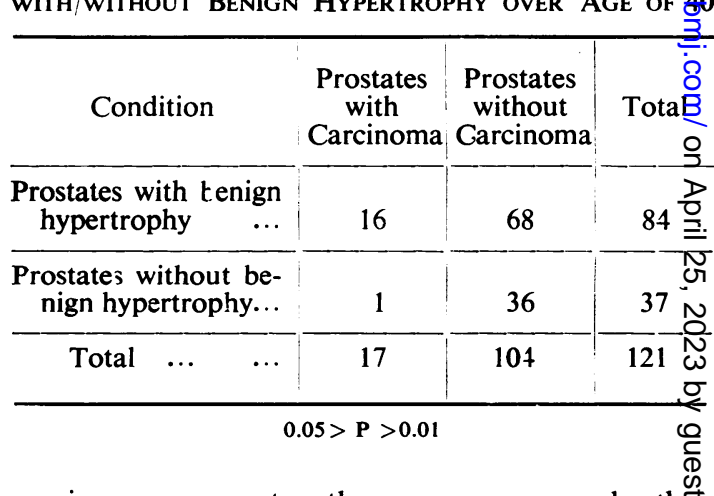

carcinoma occur together more commonly than can be explained by chance. There is a signi cant connexion between the two conditions; the coefficient of contingency calculated from the table is 0.187 and the coefficient of correlation is 0.207 ; these values give some indication of the degree of dependence of the two conditions. 


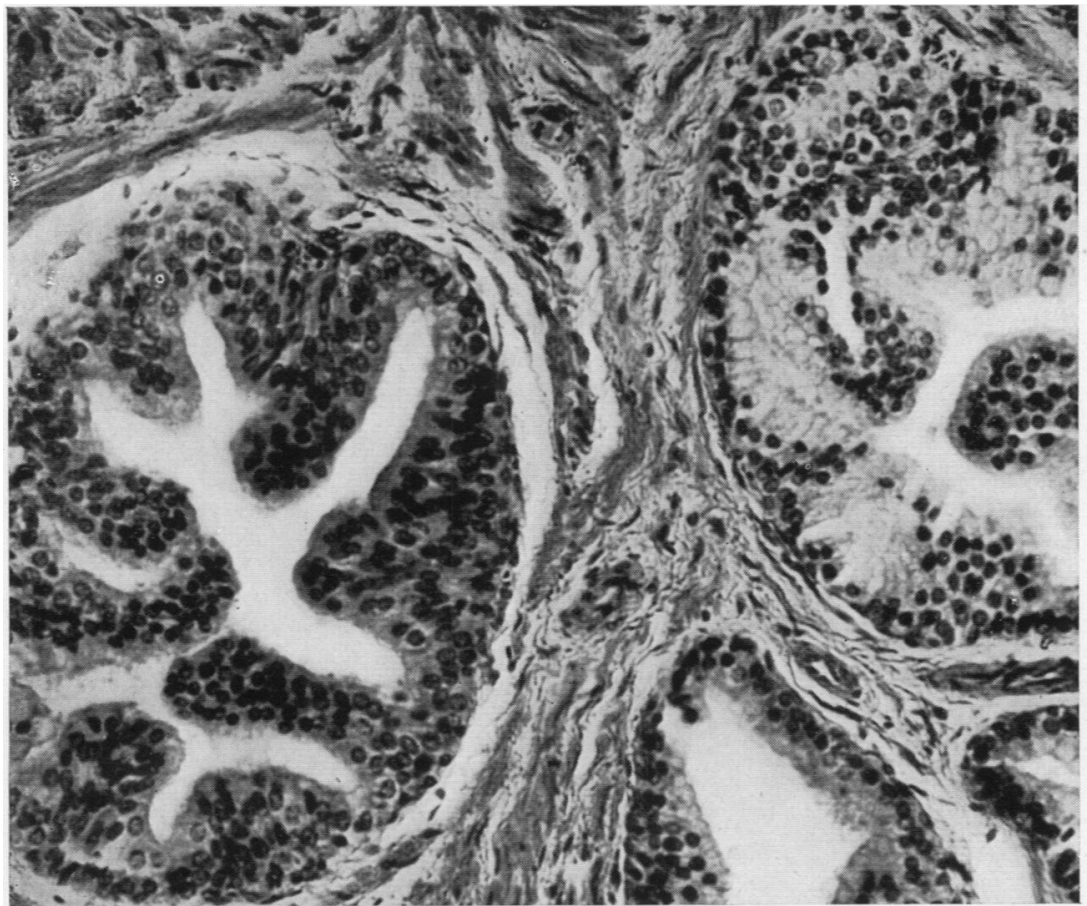

FIG. 7.-Hyperplastic acinus on left compared with normal acinus on right. $\times 260$.

2-3 ml. It would appear that the degree of benign hypertrophy was greater in glands with carcinoma than in those without it.

Precancerous Conditions.-In 12 prostates with carcinoma a characteristic type of hyperplasia was intimately associated with the tumours. The hyperplastic acini were large and composed of large cells, columnar in form, with deeply eosinophilic cytoplasm, the nuclei being strikingly large and usually oval in shape, although occasionally round, with a well - defined though delicate chromatin network, and situated centrally in the cell. The nuclei were some-

Table III shows the mean volumes of normal, hypertrophied, and carcinomatous glands. The volumes of some prostates examined were not recorded, as they had remained in fixative for a long time and shrinkage might have occurred.

TABLE III

Mean Volumes and their Standard Deviations of Normal and Abnormal Prostates

\begin{tabular}{|c|c|c|c|c|}
\hline \multicolumn{2}{|c|}{ Condition } & $\begin{array}{c}\text { Number } \\
\text { of } \\
\text { Prostates }\end{array}$ & $\begin{array}{c}\text { Mean } \\
\text { Volume } \\
\text { (ml.) }\end{array}$ & $\begin{array}{l}\text { Standard } \\
\text { Deviation }\end{array}$ \\
\hline Normal & $\ldots$ & 49 & 21.4 & 6.389 \\
\hline$\underset{\text { without }}{\text { Benign }}$ & $\begin{array}{l}\text { hypertrophy } \\
\text { carcinoma }\end{array}$ & 63 & 30.35 & 9.277 \\
\hline Carcinoma & $\ldots$ & 16 & 41.56 & 24.67 \\
\hline Tota & al $\ldots$ & 128 & & \\
\hline
\end{tabular}

The small number of glands with carcinoma prevents accurate analysis of this table, but it is interesting that carcinoma occurred more commonly in the larger glands. Except in one case the presence of the carcinoma made very little difference to the volume of the gland, at the most times elongated, filiform in shape and more pyknotic. Mitotic figures were sometimes seen. The acini were lined by more than one layer of cells, and many large cellu'ar papillae projected into the lumen. The cell outlines were blurred except that the luminal borders and the papillae appeared as solid eosinophil projections with nuclei scattered within them. The papillae were nearly always cellular; very rarely did they have a stromal core. These acini usually had a basal layer of epithelial cells and always had a normal stroma propria (Fig. 7). Occasionally the cells lining the lumen of the acinus, and only these, showed some degree of differentiation to the normal adult cell with the clear reticular cytoplasm and basal nucleus. There is a close similarity between the hyperplastic and malignant cells and particularly between the hyperplastic acini and those of the intra-acinar type of carcinoma, and there is evidence of a gradation between one and the other (Figs. 8, 9, 10).

This hyperplasia occurred not only in prostates with carcinoma but in normal glands, and particularly in those with benign hypertrophy. The amount of hyperplasia varied. Table IV shows in the whole series of 142 its incidence and extent. It can be calculated from this table that the 


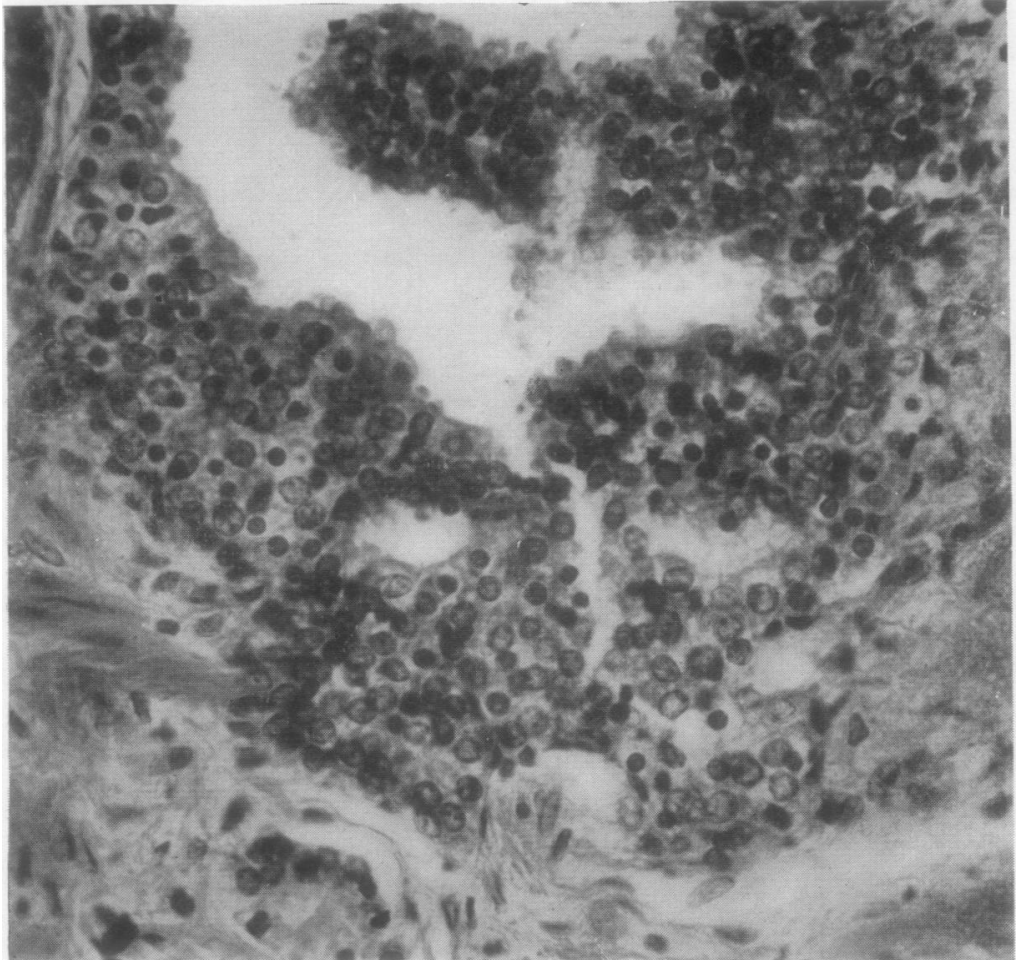

FIG. 8.--Hyperplastic acinus in! which cells have broken through the stroma propria into adjacent muscle. $\times 400$. composed of acini without a basal layer of epithelial cells, whereas in the other four no specific histological features were detected.

\section{Discussion}

It may be concluded that microscopic carcinoma of the prostate is common and occurs particularly beneath the capsule in the posterior lobe in men over the age of 60 years. It infiltrates the capsule and perineural lymphatics early.

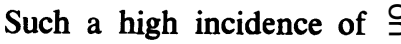
microscopic carcinoma is difficult to interpret. It is well known that some small growths in the prostate may give rise to widespread metastases (Turnbull and Worthington, 1908), and it would seem that in these latent cases there may be some factor, possibly hormonal, that is restricting growth and dissemination. incidence of this hyperplasia does not increase with age but that there is a definite increase in its incidence and extent both in benign hypertrophy and carcinoma and particularly with the latter.

It is most significant that in 41 of the 45 prostates with this hyperplasia the change occurred in the posterior lobe and was actually confined to this lobe in 27 of them. The lateral lobes were involved in 17 and the middle in one. In four cases this hyperplasia took part in "adenoma" formation, one of these being in the posterior lobe.

In one of the prostates without the specific hyperplasia the carcinoma seemed to arise in an "adenoma"

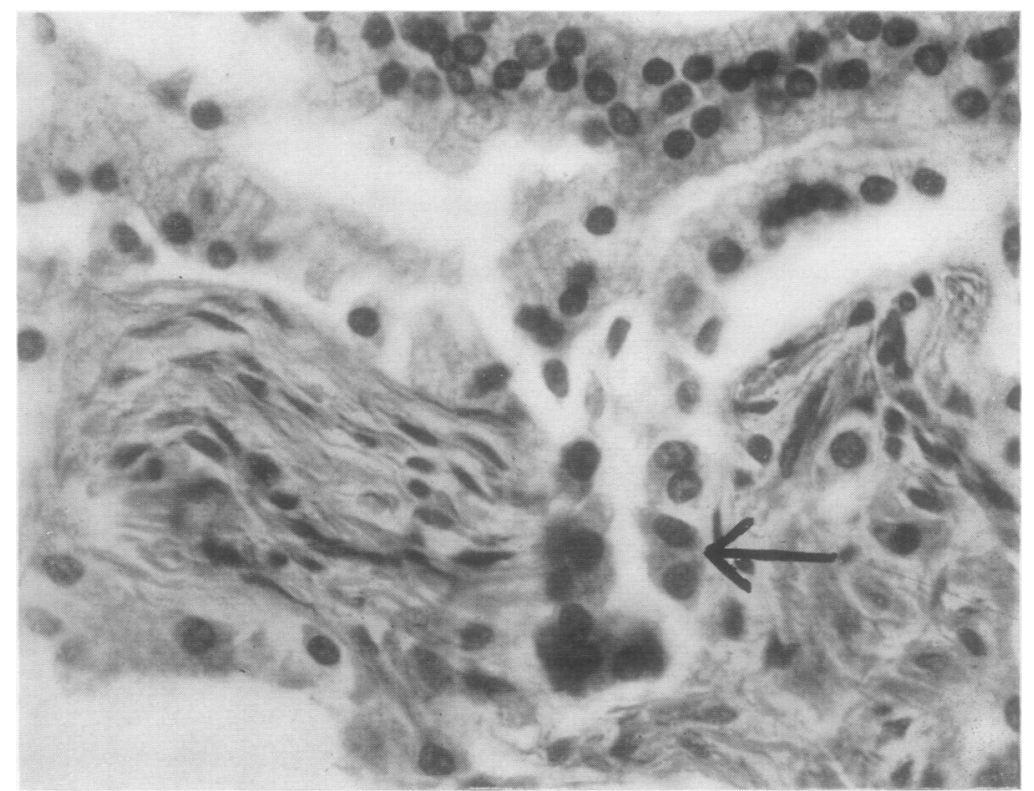

FIG. 9.-Malignant cells, indicated by arrow, "budding off" a hyperplastic acinus and rupturing the stroma propria. (Note the change in nuclear appearance.) $\times 400$. 
TABLE IV

InCidence of Hyperplasia in Normal and Abnormal Prostates

\begin{tabular}{|c|c|c|c|c|c|c|c|c|c|c|c|}
\hline \multicolumn{3}{|c|}{ Condition of Prostates } & \multicolumn{3}{|c|}{ Normal } & \multicolumn{3}{|c|}{$\begin{array}{c}\text { Benign } \\
\text { Hypertrophy }\end{array}$} & \multicolumn{3}{|c|}{ Carcinoma } \\
\hline & Age & Groups: & $15-29$ & $30-59$ & $60+$ & $15-29$ & $30-59$ & $60+$ & $15-29$ & $30-59$ & $60+$ \\
\hline \multirow[t]{4}{*}{ Degree ${ }^{*}$ of hyperplasia } & \multirow[t]{4}{*}{$\cdots$} & - & 8 & 38 & 2 & 0 & 17 & 27 & 0 & 1 & 4 \\
\hline & & + & 2 & 5 & $\mathbf{0}$ & 0 & 6 & 11 & 0 & 1 & 1 \\
\hline & & ++ & 0 & 2 & $\mathbf{0}$ & 0 & 0 & 6 & 0 & 0 & 3 \\
\hline & & +++ & 0 & 0 & 0 & 0 & 0 & 1 & 0 & 1 & 6 \\
\hline
\end{tabular}

* The extent of the hyperplasia, i.e., the number of acini showing this change, is indicated by degrees of + .

A slow rate of growth, however, does not detract from the clinical significance. Flynn (1946) describes a case of occult carcinoma of the prostate which took 12 years to become widespread and cause death.

Although the high incidence of microscopic carcinoma in the prostate is rather puzzling, it must be remembered that the prostate has been chosen for such a thorough histological investigation because of its convenient size. A high incidence of microscopic carcinoma in other organs might be revealed by a similar method of study.

The close connexion between benign hypertrophy and carcinoma of the prostate has not always been supported by other writers. Although Albarran and Hallé (1900) considered benign hypertrophy to be a precancerous condition, Moore (1935) thought that carcinoma was intimately associated with and probably derived from epithelial cells that had previously undergone senile change, and Rich (1935) that carcinoma arose more commonly from senile and atrophic glands compressed by hypertrophied areas. Muir (1934) was unable to find any predisposing cause except age, and Kahler (1939) found no connexion between carcinoma and any other condition. Objections to regarding benign hypertrophy as a precancerous condition are that it is very common, that carcinonoma rarely arises in an "adenoma," and that carcinoma occurs more commonly in the posterior lobe which is seldom affected in benign hypertrophy. The finding of a distinctive hyperplasia, frequently in the posterior lobe, which may undergo malignant change and is common to both benign hypertrophy and carcinoma, provides a closer link between the two conditions. The changes seen are similar to those described in carcinoma of the breast by Muir (1941), who showed that in certain cases intra-duct or intra-acinar hyperplasia preceded neoplasia. Such a similarity was also shown by Cheatle and Wale (1929), who

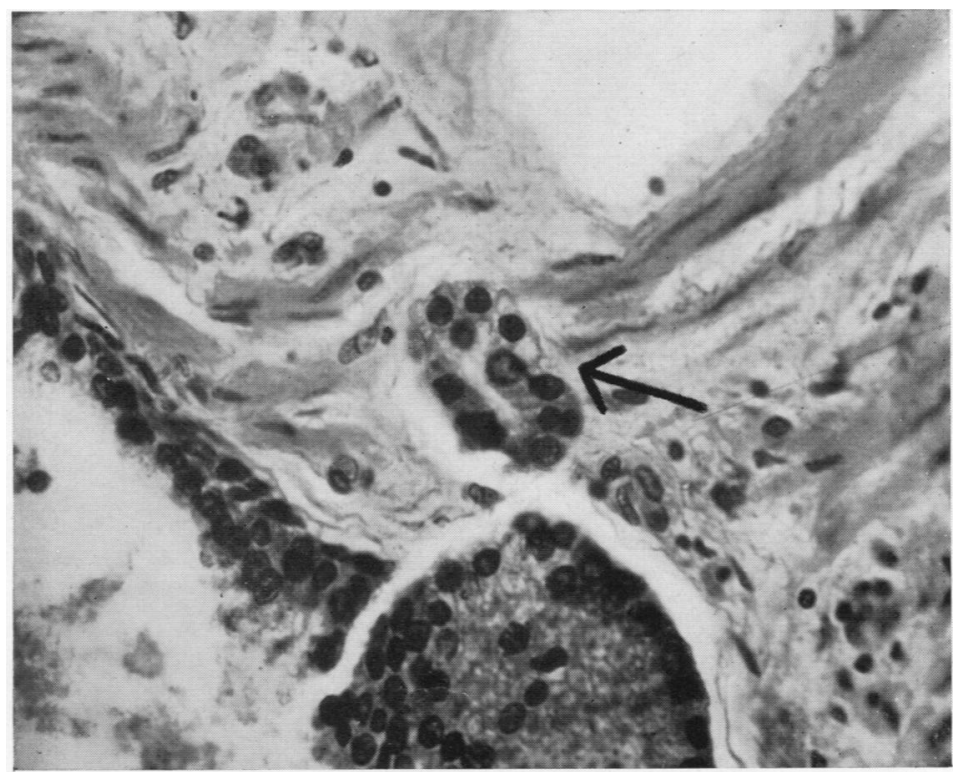

FIG. 10.-Small malignant acinus, indicated by arrow, appearing to have "budded off" from a hyperplastic acinus and ruptured adjacent muscle fibres. $\times 400$. 
believed that carcinoma of the prostate may be preceded by a "cystiphorous desquamative hyperplasia." No evidence was found that cyst formation in the prostate was preceded by desquamation, and it is not clear whether the hyperplasia described by Cheatle and Wale was similar to that seen in this study, but the ultimate conclusion appears to be the same-namely, that certain cases of carcinoma of the prostate are preceded by hyperplasia.

\section{Summary}

A detailed histological study of 142 prostates removed post-mortem was carried out and latent carcinoma found in $12 \%$.

The criteria of malignancy adopted and the histology of the carcinomata are described.

Latent carcinoma was found most commoniy beneath the capsule in the posterior lobe in men over 60 years of age. It was occasionally multifocal in origin.

Benign hypertrophy and latent carcinoma of the prostate are closely associated.
A specific form of hyperplasia is described which commonly occurs in, but is not confined to, benign hypertrophy and sometimes becomes neoplastic.

The work was carried out with the help of a grant from the Colston Research Society. I wish to thank Professor T. F. Hewer. Dr. N. G. B. McLetchie, and Dr. O. C. Lloyd for their assistance, and Dr. G. Herdan for his help with the statistical analysis of the tables. Mr. G. Rogers took the photographs.

\section{REFERENCES}

Albarran, J., and Hallé, N. (1900). Ann. Mal. Org. gén-urin.. 18. 113. Baron, E., and Angrist, A. (1941). Arch. Path., 32, 789.

Cheatle, G. L., and Wale, R. S. (1929-30). Brit. J. Surg., 17. 619.

Flynn, J. E. (1946). J. Urol., 55, 626.

Gaynor, E. P. (1938). Virchows Arch., 301, 602.

Kahler, J. E. (1939). J. Urol., 41. 557. Pathology. London. P. 448 .
Pam, A. C.

Lowsley, O. S. (1930). Amer. J. Surg., 8, 526

Luppi, J. E. (1947). Rev. Méd. Rosario, 37, 845.

Moore, R. A. (1935). J. Urol., 33, 224.

Muir, E. G. (1934). Lancet, 1, 667.

Muir, R. (1941). J. Path. Bact., 52, 155.

Muir, R. (1941). J. Path. Bact., 52, 15
Rich, A. R. (1935). J. Urol., 33, 215. Turnbull, H. M., and Worthington, R. (1908). frch. Puth. Inst.
London Hosp., 2, 175 . 